\title{
HISTÓRIA E MEMÓRIA: PROSTITUIÇÃO EM LONDRINA
}

\author{
Paulo Sérgio Micali Junior (Mestrado em História Social - UEL)
}

Prof. Dr. Richard Gonçalves André (Orientador)

\section{RESUMO}

Tomando o viés historiográfico, problematiza-se a memória ao passo que se tece uma discussão concernente à prostituição praticada em Londrina. Tal recorte se deve às ricas possibilidades de estudo inerentes a si, como os promissores paralelos passíveis de estabelecimento entre os trabalhos de Maurice Halbwachs, Michael Pollak e Pierre Nora naquilo que tange à memória coletiva, silêncio, esquecimento e a inexistência da memória, respectivamente. Para tal, pautamo-nos também em trabalhos produzidos por historiadores que se dedicaram a pesquisa e coleta de fontes - orais, fotografias, laudos criminais, periódicos e etc. - concernentes aos marginalizados e a marginalidade em Londrina, tais como Edson Holtz Leme e Fábio Martins Bueno. Ainda, ressaltamos que Londrina é uma cidade jovem, conta com apenas oitenta e um anos, e, portanto, muito do que discutimos aqui sobre prostituição, ainda são elementos presentes na cidade. Por fim, ressaltamos nossa inclinação a contribuir para com a historiografia norteparanaense, mais especificamente ao município de Londrina.

Palavras-chave: história, memória, prostituição em Londrina.

Aqueles inclinados ao ofício historiográfico consequentemente deparar-se-ão com um dos aspectos impar e dual das ciências: a possibilidade de "análise do dito e do não-dito". Para ser mais claro, a ciência; enquanto atividade humana baseada em métodos pré-definidos por meio dos quais se comprovam, testam e produzem conhecimentos; é possível mesmo diante de hiatos, ausências e descontinuidades.

Assim o afirmamos, pois, diante de um objeto de estudo marcado por lacunas, estas próprias "oferecerão pano para manga" aos pesquisadores que, de agora em diante, poderão buscar explicações para aquelas ausências. Desta forma, a própria ausência torna-se objeto de pesquisa.

Foquemos agora no campo da historiografia, mais especificamente naquilo que concerne à questão da memória. Nessa área do saber, o "não-dito", assim como nas outras ciências, é vital para a continuidade da pesquisa. Michael Pollak, sociólogo e historiador austriaco, por exemplo, dedicou-se ao estudo dessa questão e, de acordo com este pesquisador, há razões bastante complexas para o silêncio de um individuo e/ou povo, além da existência de "barreiras" que segregam memórias "marginalizadas" no universo ortodoxo.

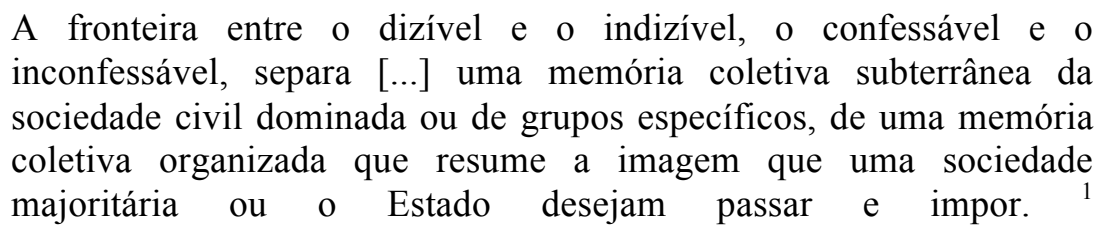

1 1989, p.8. 


\section{SEMINÁRIO DE PESQUISA EM CIÊNCIAS HUMANAS - SEPECH \\ Humanidades, Estado e desafios didático-científicos \\ Londrina, 27 a 29 de julho de 2016}

Sob esta perspectiva, a memória silenciada pode, certamente, ser compreendida enquanto marginalizada, afinal, ela destoa da "imagem oficial" difundida ou pelo Estado e/ou pela parcela majoritária da população. Neste âmbito, Maurice Halbwachs, cientista social francês que também se dedicou às questões concernentes a memória, oferece-nos um estudo do conceito de memória coletiva, cunhado por ele próprio. Ainda, a partir deste estudo, Pollak depreende que, segundo Halbwachs, "[...] a nação é a forma mais acabada de um grupo, e a memória nacional, a forma mais completa de uma memória coletiva" ${ }^{2}$, proposição reafirmada pelo historiador francês Pierre Nora, que toma a nação-memória enquanto "[...] a última encarnação da história-memória" ${ }^{3}$. Ainda de acordo com Halbwachs,

Para que a memória dos outros venha assim reforçar e completar a nossa, é preciso também, dizíamos, que as lembranças desses grupos não estejam absolutamente sem relação com os eventos que constituem o meu passado. Cada um de nós, com efeito, é membro ao mesmo tempo de vários grupos, maiores ou menores. Ora, se fixarmos nossa atenção sobre os grupos maiores, por exemplo, a nação, ainda que nossa vida e a de nossos pais ou de nossos amigos estejam compreendidas nela, não podemos dizer que a nação como tal se interesse pelos destinos individuais de cada um de seus membros. Admitamos que a história nacional seja um resumo fiel dos acontecimentos mais importantes que modificaram a vida de uma nação. Ela se distingue das historias locais, provinciais, urbanas, devido a que ela retém somente os fatos que interessam ao conjunto dos cidadãos, ou, se o quisermos, aos cidadãos como membros da nação. ${ }^{4}$

Antes de prosseguirmos em nossa discussão - que culminará em uma breve análise da prática da prostituição no município de Londrina -, faz-se necessário um esclarecimento: a memória coletiva não é resultado da somatória das memórias individuais, mas sim uma conciliação resultante de um processo de negociação estabelecido a partir delas. Em sua análise do estudo de Halbwachs, Pollak afima que

[...] [Halbwachs] insinua não apenas a seletividade de toda memória, mas também um processo de "negociação" para conciliar memória coletiva e memórias individuais: "Para que nossa memória se beneficie da dos outros, não basta que eles nos tragam seus testemunhos: é preciso também que ela não tenha deixado de concordar com as suas memórias e que haja suficientes pontos de contato entre ela e as outras para que a lembrança que os outros nos trazem possa ser reconstruída sobre uma base comum". ${ }^{5}$

Chegamos agora noutro ponto crucial para a nossa discussão. Os "pontos de contato", citados no trecho acima, são de fundamental importância para compreender-se

\footnotetext{
${ }^{2}$ Halbwachs apud Pollak, 1989, p.3

3 1993, p.12.

4 1990, p.53.

${ }^{5}$ 1989, pp.3-4.
} 


\section{SEMINÁRIO DE PESQUISA EM CIÊNCIAS HUMANAS - SEPECH \\ Humanidades, Estado e desafios didático-científicos \\ Londrina, 27 a 29 de julho de 2016}

o conceito de memória enquanto coletiva, afinal, são aqueles "locais de interseção" entre as memórias individuais que estruturam a memória coletiva. Mas, afinal, que pontos são esses? Segundo Pierre Nora, aqueles marcos nada mais são que restos, de fato:

A forma extrema onde subsiste uma consciência comemorativa numa história que a chama, porque ela a ignora. É a desritualização de nosso mundo que faz aparecer a noção. O que secreta, veste, estabelece, constrói, decreta, mantém pelo artifício e pela vontade uma coletividade fundamentalmente envolvida em sua transformação e sua renovação. Valorizando, por natureza, mais o novo do que o antigo, mais o jovem do que o velho, mais o futuro do que o passado. Museus, arquivos, cemitérios e coleções, festas, aniversários, tratados, processos verbais, monumentos, santuários, associações, são os marcos testemunhas de uma outra era, das ilusões de eternidade. ${ }^{6}$

Os "restos", portanto, são entendidos por Nora como vestígios de tempos passados que, a propósito, enquanto "lugares de memória", são passíveis de seleção por parte daqueles que buscam mantener sua memória, privando-as do desolador esquecimento. Acerca desta empreitada, Nora afirma que

Os lugares de memória nascem e vivem do sentimento que não há memória espontânea, que é preciso criar arquivos, que é preciso manter aniversários, organizar celebrações, pronunciar elogios fúnebres, notariar atas porque essas operações não são naturais. É por isso a defesa, pelas minorias, de uma memória refugiada sobre focos privilegiados e enciumadamente guardados nada mais faz do que levar à incadecência a verdade de todos os lugares de memoria. Sem vigilância comemorativa, a historia depressa os varreira. São bastiões sobre os quais se escora. Mas se o que eles defendem não estivesse ameaçado, não se teria, tampouco, a necessidade de construi-los. Se vivêssemos verdadeiramente as lembranças que eles envolvem, eles seriam inúteis. ${ }^{7}$

Desde a organização periódica de determinada festividade até a criação de museus e arquivos, as formas de manutenção da memória são inúmeras e, segundo Nora, nascem do sentimento de que não existe memória involuntária, muito pelo contrário, elas são selecionadas conscientemente por aqueles que, de alguma forma, compartilham e visam à manutenção de lugares de memória, sejam eles; de forma simultânea ou não; de ordem material, simbólica ou funcional. ${ }^{8}$ Em outras palavras, "Fala-se tanto de memória porque ela não existe mais" e "Há locais de memória porque não há mais meios de memória". 9

Ainda sobre os lugares de memória, uma breve abordagem acerca dos materiais da memória coletiva e da historia, sob a perspectiva de Jacques Le Goff, mostra-se

\footnotetext{
6 1993, pp.12-13.

7 1993, p.13.

8 1993, p.21.

9 1993, p.7,
} 


\section{SEMINÁRIO DE PESQUISA EM CIÊNCIAS HUMANAS - SEPECH \\ Humanidades, Estado e desafios didático-científicos \\ Londrina, 27 a 29 de julho de 2016}

promissora, já que essa discussão também gira em torno de questões referentes à memória coletiva e às heranças do passado. Nessa perspectiva, Le Goff discorre acerca do conceito de documento/monumento, materiais nos quais é aplicada a forma científica da memória coletiva: a história. Ao definir monumento e documento como herança do passado e escolha do historiador, respectivamente, Le Goff estabelece um evidente diálogo para com Pollack, Halbwachs e Nora naquilo que concerne à memória enquanto um campo de disputas. Como discutido, a memória não surge de forma espontânea e/ou inocente, muito pelo contrário. A memória constitui um embate de forças onde

[...] o que sobrevive não é o conjunto daquilo que existiu no passado, mas uma escolha efetuada quer pelas forças que operam no desenvolvimento temporal do mundo e da humanidade, quer pelos que se dedicam à ciência do passado e do tempo que passa, os historiadores. ${ }^{10}$

No excerto acima, é-nos afirmado que os vestígios do passado não são aquilo que de fato existiu, mas uma seleção intrinseca a embates de poder que, por sinal, são discutidos nas pesquisas de Pollak relacionadas aos sobreviventes do holocausto:

Nas histórias de vida publicadas logo depois da guerra, aparecia talvez
por ser mais imediatamente dizível do que depois de 1949. No caso de
nossas entrevistas, pudemos mostrar que o ato de relatar o evento
pessoal, atribuindo-o a outra pessoa, não atendia a uma eventual
vontade de falsear a informação, mas era simplesmente uma
transposição necessária, que permitia transmitir uma experiência
extremamente dolorosa. ${ }^{11}$

Note-se que Pollak utilizou o adjetivo "dizível”. Foquemos neste, pois há muito que se deprender desta palavra. Se há o dizível, há também o que não deve/deveria ser dito, consecutivamente. Quem ou o que assume o papel proibitivo, no entanto, varia de caso para caso. Desta forma, via de regra, questões tidas como tabus são evitados ou nem ao menos mencionados em determinados meios, como é o caso das discussões refentes aos marginalizados. Buscando uma melhor comprrensão acerda desta questão, analisaremos a seguir, mais aprofundadamente, nosso objeto de pesquisa: a prática da prostituição em Londrina.

Localizado no norte do estado do Paraná, em Londrina, cafeicultura e prostituição caminharam lado a lado e mantiveram-se intimamente ligadas no decorrer da história dessa cidade que ficou conhecida, principalmente, como capital mundial do café. As "casas de tolerância" de Londrina, entretanto, não são tão rememoradas quanto à cafeicultura. Nesse caso, a influência da moral cristã permite-nos uma melhor compreensão acerca do porquê essa memória não é tão evidente quanto a primeira. Isso não significa, no entanto, que as casas de meretrício e as prostitutas não tenham desempenhado um papel fundamental na história do município. Claude Lévi-Strauss, por exemplo, chama-nos a atenção para aquela importância, principalmente em cidades com forte tradição pioneira. Em sua passagem pela região de Londrina, o antropólogo

\footnotetext{
${ }^{10}$ LE GOFF, 1990, p. 535.

11 1992, p. 209.
} 


\section{SEMINÁRIO DE PESQUISA EM CIÊNCIAS HUMANAS - SEPECH \\ Humanidades, Estado e desafios didático-científicos \\ Londrina, 27 a 29 de julho de 2016}

francês cita o caso de Marília, uma cidade paulistana localizada a 200 quilômetros de Londrina e cuja fundação se deu por meio de um empreendimento bastante semelho ao que resultaria nesta:

[...] pois não houve uma época, por volta de 1925, em que Marilia, nascida dum empreendimento semelhante, de 600 casas construídas tinha pelo menos 100 de passe, destinadas na maioria a essas francesinhas que, juntamente com as irmãzinhas, construíram no século XIX as duas alas mestras da nossas influencia [francesa] no estrangeiro? ${ }^{12}$

Ou seja, de acordo com o antropólogo, por volta de 1925, aquela cidade fundada em 1929 - contava com, aproximadamente, seiscentos edifícios, dos quais pelo menos uma centena era destinada às "francesinhas", clara referência às prostitutas. Em outras palavras, é-nos apresentado o quadro de uma cidade cuja fundação baseou-se num empreendimento bastante semelhante ao de Londrina, próxima desta e que contava largamente com a prática da prostituição. São quase $17 \%$ dos seiscentos edifícios voltados para esse fim.

Tomar os casos de Marília e Londrina como idênticos, no entanto, é impensável. Ressaltamos que fazê-lo, em momento algum, fora nossa intenção. Todavia, o estabelecimento de paralelos e semelhanças é possível.

Analisemos agora a fala de outro pesquisador francês, Pierre Monbeig:

[...] por toda a parte, em todos os novos patrimônios prosperaram os hotéis e as pensões. Frequentemente são muito animados. Se são boas as circunstâncias econômicas, o patrimônio retoma a tradição ruídos de todas as cidades pioneiras. Encantaram-se os primeiros habitantes de Marilia, ao recordar os anos de 1924 a 1928, quando o champanhe corria a todo, quando se jogava para valer. Em 653 edifícios, somente três eram casas exclusivamente de moradia; 650, locais de comércios, dos quais 87 casas de tolerância. Lembram-se os velhos fazendeiros das "francesas" de Ribeirão Preto [...]. ${ }^{13}$

Novamente, faz--se referências as "francesas" em Marília além das estatísticas referentes ao número de edifícios e suas atribuições; números bastante próximos aos informados por Lévi-Strauss, a propósito. Já com relação à prostituição praticada em Londrina, o jornalista Marinósio Filho oferece-nos uma rica gama de informações relacionadas as décadas de 1920-30:

A zona de meretrício de Londrina, grilou-se na rua Rio Grande do Sul. A sua primeira casa de tolerância ninguém se lembra a quem pertenceu. Os mais antigos contam que foi um dos trabalhadores da Companhia de Terras, pernambucano ou alagoano, o portador da primeira "ninfa" para cá. Numa das viagens a Ourinhos, conheceu uma mulher e a trouxe com promessas de que dinheiro, aqui "dava que nem jerimum". A mulher, Maria Loira, Palmira Preta, ou Rosy,

\footnotetext{
12 LEVI-STRAUSS, 1986, p.119 apud BENATTI, 1996, p.92.

13 op. cit., p.16 apud BENATTI, 1996, p.92.
} 


\section{SEMINÁRIO DE PESQUISA EM CIÊNCIAS HUMANAS - SEPECH \\ Humanidades, Estado e desafios didático-científicos \\ Londrina, 27 a 29 de julho de 2016}

entusiasmou-se e veio [...] Dentro de uma semana, os cômodos de palmito já estavam de pé e houve inauguração com churrascada e muita cerveja: "O movimento, uma coisa de louco". Semana seguinte, a "moça" viajou até Ourinhos e trouxe consigo umas quatro mais. Bonitas, "linha de frente", escolhidas a dedo. A notícia das novas "mercadorias", rapidamente, passou de boca em boca. Era o comentário do lugarejo [...] Oficialmente, começa aí a história da rua Rio Grande do Sul. "Casas" fincadas. Grupos de "borboletas" chegando. Descobriram "o tesouro do rei". ${ }^{14}$

O trecho acima sugere que um dos primeiros meretrícios instalado onde hoje é Londrina pertencia, talvez, a um dos trabalhadores da Companhia de Terras Norte Paraná (CTNP), uma empresa colonizadora, financiada pelo capital inglês e que atuou na região em meados de 1930. Desta forma, Marinósio Filho sugere a existência de, ao menos, um meretrício antes mesmo da fundação oficial de Londrina - que se deu em 1934 - onde hoje fica a região central da cidade.

Ainda, é interessante notar que, não muito longe da rua Rio Grande do Sul, havia, onde hoje é a rodoviária de Londrina, a Vila Matos, uma "zona de meretrício" bastante famosa em meados da década de 1970. Essa proximidade, a propósito, não é por acaso. De acordo com o historiador Antônio Paulo Benatti

O "primeiro quadrilátero do amor" funcionou na rua Rio Grande do Sul, que [...] desde cedo teve a vocação de ser a principal artéria da zona licenciosa da cidade. Nessa rua, a zona funcionaria até finais da década de quarenta (1948 ou 1949), quando, por se achar já em pleno centro da cidade, foi fechada pelas autoridades e removida para a Vila Matos. ${ }^{15}$

Sobre o "deslocamento do quadrilátero do amor" da rua Rio Grande do Sul para a Vila Matos, Fábio Martins Bueno afirma que:

A Vila Matos surgiu em consequência da expulsão das "casas de tolerância" das regiões mais próximas do centro da cidade. Segundo o jornalista Marinósio Neto, em 1949, o então delegado Edmundo Mercer Junior, atendendo as inúmeras queixas, baixou uma portaria para que, num prazo de trinta dias, a zona do meretrício, que se encontrava na rua Rio Grande do Sul, fosse transferida para a Vila Matos. O processo foi investigado pelo historiador Edson Holtz Leme: “[...] a Vila Matos, nasceu distante do centro, porém próximo do olhar vigilante da polícia. Como uma verdadeira "cidade proibida", o novo endereço da zona cresceu sob o estigma da marginalidade [...]. ${ }^{16}$

É interessante atentarmos à fala de Maronósio Neto. De acordo com o jornalista, em fins da década de 1940 uma série de queixas levou o então delegado de Londrina a "expulsar" as "casas de tolerância" do centro da cidade, ou seja, buscou-se não a

\footnotetext{
${ }^{14}$ op. cit., p.6 apud BENATTI, 1996, p.91.

15 1996, p. 103.

${ }^{16} 2011$, p. 29.
} 


\section{SEMINÁRIO DE PESQUISA EM CIÊNCIAS HUMANAS - SEPECH \\ Humanidades, Estado e desafios didático-científicos \\ Londrina, 27 a 29 de julho de 2016}

extinção daqueles estabelecimentos, mas o seu deslocamento para longe do centro urbano. Nesta perspectiva, talvez seja possível estabelecer um paralelo entre essa ação jurídica ao o ato de ignorar o elefante na sala ou à uma tentativa de silenciar uma memória incomoda. ${ }^{17}$

Ainda nessa discussão, a dispersão daquelas antigas casas de tolerância culminou no seu reagrupamento num conjunto de habitações que ficou conhecido como Vila Velha ou Vila Matos, longe do centro urbano, como ressalta Edson Holtz. Todavia, o rápido crescimento de Londrina viria a levar por água a baixo os planos do delegado Edmundo Mercer Junior. Bastou menos de duas décadas para que, com o vertiginoso crescimento da cidade, o centro "esbarrasse" com a Vila Matos e, assim, desse-se inicio a uma nova cruzada contra os marginalizados.

Desta vez, no entanto, o "ataque" partiu não da polícia judiciária, mas do próprio chefe do executivo municipal, como afirmou o jornalista Edson Maschio em entrevista concedida à Fábio Martins Bueno:

[...] a cidade [Londrina] cresceu e a Vila [Matos] ficou dentro da cidade, ficou plantada dentro da cidade. Quando o Antônio Belinati assumiu, em 1976, ele, num acesso de moralismo, resolveu fechar a zona do meretrício, e até acertou, porque ela estava dentro da própria cidade. Então [...] o delegado, que era então o Bukowski, deu trinta dias para as cafetinas mudarem, procurarem outro lugar [...] Nessa ocasião, surgiu também um plano para a zona do meretrício lá onde é a Viação Garcia hoje. Eles queriam fazer um loteamento, mas não deu certo, acabaram fechando a zona do meretrício e as casas se espalharam pela cidade. Hoje é comum você encontrar os inferninhos ai por esses bairros. Aqui perto da minha casa tem quatro ou cinco $[\ldots] .{ }^{18}$

Novamente, buscou-se transferir uma parcela marginalizada da população para fora do centro da cidade, ação essa claramente marcada por violência simbòlica, pois, não apenas transfere-se uma parcela marginalidade da população para outro espaço, mas excomunga-a do centro urbano, expulsa-a de um local onde "não deveriam estar". Nas palavras de Pollak, esta disputa de poderes

Embora na maioria das vezes esteja ligada a fenômenos de dominação, a clivagem entre memoria oficial e dominante e minorias subterrâneas, assim como a significação do silencio sobre o passado, não remete forçosamente a oposição entre Estado dominador e sociedade civil. Encontramos com mais frequência esses problema nas relações entre grupos minoritários e sociedade englobante. ${ }^{19}$

Dessa forma, demoliu-se a Vila Matos, "apagou-se" uma memória incômoda, e construiu-se por cima um edifício de estrutura moderna, complexa, projetada pelo arquiteto Oscar Niemeyer: o quinto e atual terminal rodoviário de Londrina. Sobre a desapropriação dos terrenos e a extinção da Vila Matos, Fabio Matins Bueno afirma que

\footnotetext{
${ }^{17}$ Pollak, 1989

${ }^{18} 2011$, p. 38.

19 1989, p.5.
} 


\section{SEMINÁRIO DE PESQUISA EM CIÊNCIAS HUMANAS - SEPECH \\ Humanidades, Estado e desafios didático-científicos \\ Londrina, 27 a 29 de julho de 2016}

O primeiro passo oficial para a demolição oficial para a demolição da Vila Matos ocorreu com um decreto municipal de 1977, que tornou os terrenos que compunham parte da Vila Matos [...] de utilidade pública. Previa-se que a desapropriação dos terrenos poderia ser de forma amigável ou judicial. Todavia, essa relação entre os moradors da Vila Matos que "faziam" a noite" e o poder público já não fora, por vezes, amigável. A primeira sequencia dessa peleja ocorreu em 1966, quando o delegado [...] fechou as casas que ali haviam e "[...] onde há cerca de 20 anos vinham funcionando ininterruptamente em lupanares, boates, restaurantes e botequins", diz o texto da Folha de Londrina. ${ }^{20}$

Como afirma Edson Maschio, não foi o fim da prostituição, ela apenas espalhouse e, ainda hoje, é motivo polêmicas. Em 2013, por exemplo, a discussão concernente ao afastamento da prostituição do centro de Londrina volta a ser motivo de discussão. Dessa vez, a iniciativa partiu do vereador londrinense Roberto $\mathrm{Fu}$, que se propôs a discutir, junto à prefeitura municipal, formas de retirar a prostituição dos bairros residenciais, afastando-a da cidade. De acordo com o periódico Gazeta do Povo, "[...] a preocupação nasceu de queixas de moradores das imediações da Avenida Leste-Oeste, que o convidaram [Roberto Fu] para visitar o local [...]. Cogitou-se, inclusive, a criação de um local voltada a prostituição, mas que não é um prostibulo, como ressalta o vereador: "Eu não falo em criar um prostibulo, mas em levar esse pessoal para um local tranquilo, que seja bom para eles [pessoas que se prostituem] e para os moradores [...]". 21

Todavia, a proposta do vereador, até o momento, não se concretizou. Já a Avenida Leste-Oeste, esta constitui um dos maiores focos de prostituição em Londrina atualmente. Nela, travestis e mulheres que se prostituem dividem espaço entre as calçadas, seja noite ou dia.

\section{REFERÊNCIAS BIBLIOGRÁFICAS}

BENATTI, Antônio Paulo. O Centro e as margens: Boemia e prostituição na “capital mundial do café" (Londrina: 1930-1970). 1996. Dissertação (Mestrado em História) - UFPR, Curitiba, 1996.

BUENO, Fábio Martins. O caso Navalhada: invenção e memória de um rei do crime. 2011. Dissertação (Mestrado em História Social) - Universidade Estadual de Londrina, Londrina, 2011.

HALBWACHS, Maurice. A memória coletiva. São Paulo: Editora Revista dos Tribunais LTDA. 1990.

LE GOFF, J. História e memória. 2. Ed. Campinas: Editora da UNICAMP, 1990.

\footnotetext{
${ }^{20} 2011$, p.39.

${ }^{21}$ VEREADOR..., 2013.
} 


\section{SEMINÁRIO DE PESQUISA EM CIÊNCIAS HUMANAS - SEPECH \\ Humanidades, Estado e desafios didático-científicos \\ Londrina, 27 a 29 de julho de 2016}

NORA, Pierre. Entre Memória e História: a problemática dos lugares. In: Projeto História. Revista do Programa de Estudos Pós-Graduação em História do Departamento de História da PUC. São Paulo, 1993.

POLLAK, Michael. Memória, Esquecimento, Silêncio. In: Estudos Históricos. Rio de Janeiro, vol. 2, n. 3, p. 3-15, 1989.

vol. 5, n. 10, p. $200-2015,1992$.

Memória e identidade social. In: Estudo Históricos. Rio de Janeiro,

VEREADOR DEFENDE CRIAÇÃO DE ÁREA PARA PROSTITUIÇÃO EM LONDRINA. Gazeta do Povo. Curitiba, 14 de fev. 2013. Disponível em: < http://www.gazetadopovo.com.br/vida-e-cidadania/vereador-defende-criacao-de-areapara-prostituicao-em-londrina-71stzv9mp1m0klm5capmn1isp $>$. Acesso em: 28 de mar. 2016. 